\title{
Post-SARS-CoV-2 vaccination venous sinus thrombosis: a literature review of 308 cases
}

\author{
Josef Finsterer $^{1^{*}}$ (10) and Sinda Zarrouk ${ }^{2}$
}

\begin{abstract}
There is accumulating evidence that SARS-CoV-2 vaccinations can be complicated by venous sinus thrombosis (VST). This review aimed at summarising and discussing previous and recent advances regarding the diagnosis, pathogenesis, treatment, and outcome of post-SARS-CoV-2 vaccination VST. At least 308 patients with post-SARS-CoV-2 vaccination VST have been reported as per the end of July 2021. Ages among these 308 patients ranged between 22 and 81 years, 69 were male and 197 were female. Post-SARS-CoV-2 vaccination VST most commonly occurred with the ChAdOx1-S vaccine followed by the BNT126b2 vaccine. In the vast majority of cases, VST occurred after the first dose. Only in six patients did VST occur after the second dose. Latency between vaccination and onset of VST ranged between 0 and 24 days. Regarding treatment, most patients received heparin followed by oral anticoagulants. Seven patients received IVIGs and six patients received steroids because of concomitant vaccine-induced immune thrombotic thrombocytopenia. Complete recovery was reported in 5 patients. Partial recovery was reported in 9 patients. Eight patients were alive or discharged. Sixty-two patients died. The outcome was not specified in the remainder. In conclusion, SARS-CoV-2 vaccinations can be complicated by VST. There is female preponderance and the outcome is frequently poor.
\end{abstract}

Keywords: SARS-CoV-2, Coronavirus, COVID-19, Thrombosis, Hypercoagulability, Covid vaccines

\section{Main text}

In SARS-CoV-2 infected, the increased risk of thrombosis is explained by virus-induced endotheliopathy or coagulopathy [1]. Invasion of the virus into endothelial cells causes their dysfunction or disruption. Dysfunction of endothelial cells leads to reduced action of thrombomodulin, which reduces coagulation in normal quantities. Disruption of endothelial cells leads to release of the plasminogen activator inhibitor-1 (PAI-1), which blocks the action of proteins that cause clot lysis and consecutively reduce the possibility of bleeding. Thus, increased levels of PAI-1 in COVID-19 enhance coagulopathy. Thrombosis in COVID-19 can be also explained by the increased Von Willebrand factor, which enhances platelet adherence and stabilises blood clots. Another mechanism

\footnotetext{
${ }^{*}$ Correspondence: fifigs1@yahoo.de

${ }^{1}$ Klinik Landstrasse, Messerli Institute, Postfach 20, 1180 Vienna, Austria Full list of author information is available at the end of the article
}

explaining thrombosis in COVID-19 is the increased release of inorganic phosphate residues from thrombocytes, stimulating the release of factor $\mathrm{V}$ and factor XI. Since cytokines and chemokines, which are excessively released in COVID-19 patients, activate macrophages, the increased macrophage count also increases the risk of clot formation [1].

Venous sinus thrombosis (VST) has been repeatedly reported as a complication of SARS-CoV-2 infections [2, 3]. Additionally, there is accumulating evidence that VST can be also a complication of SARS-CoV-2 vaccinations [4-6]. Upon anticoagulation with heparin or oral anticoagulants, respectively, symptoms and signs of VST usually resolve, but a number of fatalities have been reported as well. Particularly, in case VST is associated with thrombocytopenia, the outcome can be fatal or unfavourable (Table 1). Though the pathophysiological mechanism underlying the development of thrombosis after SARS-CoV-2 vaccinations has not been fully elucidated, 
Table 1 Patients with post-SARS-CoV-2 vaccination VST reported in the literature

\begin{tabular}{|c|c|c|c|c|c|c|c|c|}
\hline Age & Sex & Dose & Company & locSVT & Latency (days) & Therapy & Outcome & References \\
\hline 53 & $f$ & $1 s t$ & A & Cavernous & 11 & Intubation, platelets & Death & [9] \\
\hline 55 & $\mathrm{~m}$ & 1st & A & Cavernous & 8 & Steroids, argatroban & Death & [9] \\
\hline $30^{*}$ & $f$ & $1 s t$ & A & Transverse, sigmoid & 7 & Argatroban, IVIG & $P R$ & [10] \\
\hline 30 & $f$ & $1 s t$ & A & $\mathrm{nr}$ & 9 & $\begin{array}{l}\text { Tinzaparin, rivaroxa- } \\
\text { ban }\end{array}$ & $P R$ & {$[11]$} \\
\hline $27^{*}$ & $\mathrm{~m}$ & $1 s t$ & A & $\mathrm{nr}$ & 2 & Dabigatran, IVIG & Death & {$[12]$} \\
\hline $54^{*}$ & $\mathrm{~m}$ & $\mathrm{nr}$ & A & $\mathrm{nr}$ & 14 & $\begin{array}{l}\text { Danaparoid, IVIG, } \\
\text { DOAC }\end{array}$ & Alive & [13] \\
\hline 49 & $\mathrm{~m}$ & $1 s t$ & $P$ & Transverse, sigmoid & 16 & Clexane, apixaban & Alive & {$[14]$} \\
\hline 69 & $f$ & $1 s t$ & A & Sigmoid, SSS & 11 & $\mathrm{nr}$ & Death & [5] \\
\hline 32 & $\mathrm{~m}$ & $1 s t$ & A & SSS & 9 & None & Death & {$[14]$} \\
\hline $25^{*}$ & $\mathrm{~m}$ & $1 s t$ & A & SSS & 6 & $\begin{array}{l}\text { Heparin, platelets, IVIG, } \\
\text { steroids }\end{array}$ & Death & {$[14]$} \\
\hline 22 & $f$ & $1 s t$ & A & SSS, transverse & 4 & $\begin{array}{l}\text { Enoxaparin, dabi- } \\
\text { gatran }\end{array}$ & $P R$ & [15] \\
\hline 46 & $f$ & $1 \mathrm{st}$ & A & $\begin{array}{l}\text { SSS, sigmoid, trans- } \\
\text { verse }\end{array}$ & 8 & $\begin{array}{l}\text { Danaparoid, dabi- } \\
\text { gatran }\end{array}$ & PR & {$[15]$} \\
\hline 36 & $f$ & $1 \mathrm{st}$ & A & SSS, straight & 7 & $\begin{array}{l}\text { Enoxaparin, dabi- } \\
\text { gatran }\end{array}$ & $C R$ & {$[15]$} \\
\hline 50 & $\mathrm{~m}$ & $1 s t$ & A & Transverse, sigmoid & 7 & Craniotomy & Death & {$[16]$} \\
\hline 61 & f & $\mathrm{nr}$ & A & $\mathrm{nr}$ & 14 & Enoxaparin & Discharged & {$[17]$} \\
\hline 40 & $\mathrm{~m}$ & $1 \mathrm{st}$ & A & $\mathrm{nr}$ & 14 & Enoxaparin, apixaban & Discharged & {$[17]$} \\
\hline 50 & $\mathrm{~m}$ & 1st & A & SSS, sigmoid & 7 & $\begin{array}{l}\text { Enoxaparin, crani- } \\
\text { otomy }\end{array}$ & Death & [18] \\
\hline 42 & $f$ & $1 s t$ & A & SSS, straight sigmoid & 0 & $\begin{array}{l}\text { Enoxaparin, crani- } \\
\text { otomy }\end{array}$ & Coma & [18] \\
\hline 55 & $f$ & 2nd & $P$ & Straight, sigmoid & 1 & Enoxaparin & Death & {$[18]$} \\
\hline 32 & $f$ & $1 \mathrm{st}$ & A & Straight, sigmoid & 1 & Fondaparinux, steroids & Death & [18] \\
\hline 35 & $f$ & $1 s t$ & A & SSS, straight sigmoid & 6 & $\begin{array}{l}\text { Enoxaparin, steroids, } \\
\text { PE }\end{array}$ & Coma & [18] \\
\hline 51 & f & $1 \mathrm{st}$ & A & Straight, sigmoid & 10 & Ventriculostomy & Death & [18] \\
\hline 64 & $\mathrm{~m}$ & $1 \mathrm{st}$ & A & SSS, straight, sigmoid & 4 & Enoxaparin & $C R$ & [18] \\
\hline 40 & f & $1 \mathrm{st}$ & A & SSS, straight sigmoid & 5 & Fondaparinux & $P R$ & [18] \\
\hline 49 & f & $1 s t$ & A & straight, sigmoid & 11 & Enoxaparin & $P R$ & [18] \\
\hline 54 & f & $1 s t$ & A & SSS, Galen & 2 & Enoxaparin, steroids & Death & [18] \\
\hline 55 & f & $1 s t$ & A & Jugular & 6 & $\begin{array}{l}\text { Fondaparinux crani- } \\
\text { otomy }\end{array}$ & Death & [18] \\
\hline 54 & $f$ & $\mathrm{nr}$ & A & Labbe, Galen & 12 & Intubation & Death & {$[20]$} \\
\hline 39 & $f$ & $1 \mathrm{st}$ & A & Sigmoid, transverse & 6 & $\begin{array}{l}\text { Danaparoid dabi- } \\
\text { gatran, IVIG }\end{array}$ & $C R$ & {$[20]$} \\
\hline $24^{*}$ & $f$ & $1 \mathrm{st}$ & A & Cortical & 8 & $\begin{array}{l}\text { Argatroban, steroids, } \\
\text { IVIG }\end{array}$ & $C R$ & {$[21]$} \\
\hline 32 & $f$ & $1 \mathrm{st}$ & A & $\mathrm{nr}$ & 11 & $\mathrm{nr}$ & Death & {$[22]$} \\
\hline $29^{*}$ & $\mathrm{~m}$ & $1 s t$ & A & Sigmoid, transverse & 9 & IVIG, agratroban & Recovery & [23] \\
\hline$>40$ & $\mathrm{nr}$ & $\mathrm{nr}$ & J & Transverse, sigmoid & 6 & $\mathrm{nr}$ & ND & {$[23]$} \\
\hline $18-39$ & $\mathrm{nr}$ & $\mathrm{nr}$ & J & Transverse, sigmoid & 9 & $\mathrm{nr}$ & Discharged & [23] \\
\hline $18-39$ & $\mathrm{nr}$ & $\mathrm{nr}$ & J & SSS, straight, & 8 & $\mathrm{nr}$ & ND & [23] \\
\hline $18-39$ & $\mathrm{nr}$ & $\mathrm{nr}$ & J & Transverse, sigmoid & 8 & $\mathrm{nr}$ & Discharged & [23] \\
\hline $18-39$ & $\mathrm{nr}$ & $\mathrm{nr}$ & J & Transverse, sigmoid & 6 & $\mathrm{nr}$ & ND & [23] \\
\hline$>40$ & $\mathrm{nr}$ & $\mathrm{nr}$ & J & Transverse, straight & 13 & $\mathrm{nr}$ & ND & [23] \\
\hline $18-39$ & $\mathrm{nr}$ & $\mathrm{nr}$ & J & $\begin{array}{l}\text { SSS, straight, trans- } \\
\text { verse }\end{array}$ & 15 & $\mathrm{nr}$ & ND & [23] \\
\hline $18-39$ & $\mathrm{nr}$ & $\mathrm{nr}$ & J & Transverse, sigmoid & 10 & $\mathrm{nr}$ & Discharged & [23] \\
\hline
\end{tabular}


Table 1 (continued)

\begin{tabular}{|c|c|c|c|c|c|c|c|c|}
\hline Age & Sex & Dose & Company & locSVT & Latency (days) & Therapy & Outcome & References \\
\hline$>40$ & $\mathrm{nr}$ & $\mathrm{nr}$ & J & SSS, cortical & 7 & $\mathrm{nr}$ & ND & [23] \\
\hline $18-39$ & $\mathrm{nr}$ & $\mathrm{nr}$ & J & $\begin{array}{l}\text { Transverse, SSS, } \\
\text { sigmoid }\end{array}$ & 7 & $\mathrm{nr}$ & ND & [23] \\
\hline $18-39$ & $\mathrm{nr}$ & $\mathrm{nr}$ & J & Transverse, sigmoid & 11 & $\mathrm{nr}$ & ND & [23] \\
\hline$>40$ & $\mathrm{nr}$ & $\mathrm{nr}$ & J & Transverse, sigmoid & 6 & $\mathrm{nr}$ & Discharged & [24] \\
\hline 51 & $\mathrm{~m}$ & $1 s t$ & C & SSS, transverse & 6 & Heparin, warfarin & $P R$ & [25] \\
\hline 40 & $f$ & $1 s t$ & J & $\mathrm{nr}$ & 5 & Bivalirudin & $C R$ & [26] \\
\hline 36 & $f$ & $1 \mathrm{st}$ & A & SSS & 14 & Enoxaparin & Death & [27] \\
\hline 25 & $f$ & $1 \mathrm{st}$ & A & Cortical & 12 & $\mathrm{nr}$ & $\mathrm{nr}$ & [28] \\
\hline $50^{*}$ & $\mathrm{~m}$ & $1 s t$ & A & Transverse, sigmoid & 14 & Desirudin & $P R$ & [29] \\
\hline $30^{*}$ & $f$ & $1 \mathrm{st}$ & A & None & 8 & Tinzaparin & $P R$ & [11] \\
\hline \multirow[t]{2}{*}{$\Theta 46.7(n=45)$} & $35 f$ & 1st (42) & $\mathrm{A}(n=37)$ & $\mathrm{nr}$ & $\mathrm{nr}$ & $\mathrm{nr}$ & $\mathrm{nr}$ & [30] \\
\hline & & 2nd (3) & $\mathrm{P}(n=8)$ & & & & & \\
\hline $32-81(n=213)$ & $\begin{array}{l}138 \mathrm{f} \\
46 \mathrm{~m}\end{array}$ & 1st (except 2) & $\begin{array}{l}\mathrm{P}(n=25) \\
\mathrm{M}(n=1) \\
\mathrm{A}(n=187)\end{array}$ & $\mathrm{nr}$ & $2-21 d$ & $\mathrm{nr}$ & Death $(n=46)$ & [31] \\
\hline
\end{tabular}

A: ChAdOx1-S, C: ChAdOx1-S from India, CR: complete recovery, DOAC: direct oral anticoagulant, locSVT: location of venous sinus thrombosis, ip: in preparation, IVIG: intravenous immunoglobulins, J: JNJ-78436735, M: mRNA-1273, ND: not discharged, nr: not reported, P: BNT126b2, PE: plasma exchange, PR: partial recovery at discharge or late follow-up (patient had not reached his pre-morbid condition), SSS: superior sagittal sinus, * associated with immune thrombocytopenia

there are indications that the immune response towards the vaccine creates a state of hypercoagulability similar to hypercoagulability in SARS-CoV-2 infections [7], but hypocoagulability has been also reported [8]. This review aimed at summarising and discussing previous and recent advances regarding the diagnosis, pathogenesis, treatment, and outcome of post-SARS-CoV-2 vaccination venous sinus thrombosis.

A literature search was conducted in the databases PubMed and Google Scholar using the search terms "SARS-CoV-2 vaccination", "mRNA based vaccine", "vector-based vaccine" combined with "side effect", "adverse reaction", "thrombosis", "venous sinus thrombosis", and "cerebral veins". Additionally, reference lists of available articles were checked for further appropriate references. Included were articles which provided detailed information about individual patients experiencing a VST time-linked to the first or second dose of a SARS-CoV-2 vaccine. Excluded were abstracts and proceedings. Four unpublished cases were not included. Only articles written in English were considered.

At least 308 patients with post-SARS-CoV-2 vaccination VST have been reported as per the end of July 2021 (Table 1) [5, 9-31] Age of these 308 patients ranged between 22 and 81 years. Gender was reported in 270 patients and was male in 69 and female in 197 patients. VST was most frequently reported after application of the ChAdOx1-S vaccine followed by the BNT126b2 and the JNJ-78436735 vaccines. In the vast majority of cases, VST occurred already after the first dose of the vaccine. Only in six patients did VST occur after the second dose. Latency between vaccination and onset of VST was reported in 263 patients and ranged between 0 and 24 days. Treatment of VST was reported in only 35 patients. Most patients received heparin followed by oral anticoagulants. Seven patients received IVIGs and six patients steroids because of concomitant vaccineinduced immune thrombotic thrombocytopenia [27]. Complete recovery was reported in only 5 patients. Partial recovery was reported in 9 patients. The outcome was reported as "alive" in two patients, as "coma" in one patient, and as "discharged" in 6 patients. Sixty-two patients died (Table 1). The outcome was not specified in the remaining patients.

This review shows that VST is indeed a potential complication of SARS-CoV-2 vaccinations usually after the first dose, that VST as a complication of SARS-CoV-2 vaccinations occurs at any age and with female preponderance, that the latency between vaccination and onset of VST ranges between 0 and 24 days, and that VST can be associated with immune thrombocytopenia, whether VST and SARS-CoV-2 vaccinations are causally related remains speculative, but there are several arguments for and against causality. Arguments in favour of a causal relation are (1) that VST occurs time-linked to the vaccination within 24 days after the first or second jab; (2) that thrombotic events have been reported as a complication of SARS-CoV-2 vaccinations in several studies; (3) that SARS-CoV-2 vaccinations can be complicated by hypercoagulability [7], and (4) that post-SARS-CoV-2 
vaccination VST has been reported in over 300 patients as per the end of June 2021 (Table 1). Hypercoagulability after SARS-CoV-2 vaccinations can be explained by direct activation of platelets, enhancing coagulation, by indirect activation of endothelial cells, shifting endothelium from an anti-thrombotic to a pro-thrombotic state, and by direct activation of complement pathways, promoting thrombin generation [32]. A pro-coagulant state after SARS-CoV-2 vaccinations could be also explained by increased blood viscosity due to activation of the coagulation pathways. Furthermore, complement consumption, which can be found during the immune response against the virus or the vaccine, may rapidly enhance monocyte tissue factor pro-coagulant activity and thus immuno-thrombosis [33]. Hypercoagulability may not only develop in patients with comorbidities, but also in previously healthy subjects. Arguments against a causal relation are that some studies did not find hypercoagulability after SARS-CoV-2 vaccinations [9], that millions of subjects have been vaccinated without experiencing a thrombotic event, and that the overall incidence/prevalence of VST has apparently not increased when comparing non-COVID and vaccination periods However, mild or small VST may go undiagnosed and undetected as most patients with post-vaccination headache or other complaints do not undergo cerebral imaging with contrast medium and determination of the D-dimer why the true prevalence of post-vaccination VST is expected to be higher than anticipated.

The pathophysiological background of VST following immunisation against the SARS-CoV-2 virus is poorly understood. A possible mechanism could be that the vaccine triggers the formation of anti-platelet factor- 4 antibodies, which induce thrombocytopenia with dysfunctional thrombocytes [34]. It is also conceivable that the immunogenic component of the vaccine triggers the formation of antibodies which in turn cross-react with membrane-bound or soluble proteins involved in thrombus formation. Thus, an antibody cross-reaction may be the most likely causal link between VST and immunisation to SARS-CoV-2 [35]. The development of VST within $24 \mathrm{~h}$ after the vaccination [10] could be explained by a subclinical pre-morbid hypercoagulable state. The reason why VST occurred already after the first jab remains elusive, but it can be speculated that the immune reaction against the vaccine starts as soon as the antigen is presented. The immune system will not wait until the second jab. The reason why VST was reported only in association with five brands is unknown, but it can be speculated that the more exotic vaccines are not widely approved in countries where publication activity is high.

Whether patients with post-vaccination VST and vaccine-induced thrombotic thrombocytopenia should not receive heparin is unsolved, but there is increasing evidence that heparin should be avoided in these patients [36]. Some studies even recommend the administration of steroids, intravenous immunoglobulins (IVIGs) and antidotes against the platelet factor-4 [37].

A limitation of the review is that insufficient individual data were reported in several articles, particularly the one by See and colleagues (Table 1) [24]. The article by Bikdeli and colleagues was not included in the evaluation as no individual data were provided for the 77 cases with post-vaccination VST reported by the Medicines and Healthcare Products Regulatory Agency (MHPRA). For the same reason, the six cases reported by the Centers for Disease Control and Prevention (CDC) were excluded. The three cases reported by the Society of Vascular and Interventional Neurology were excluded because patients experienced VST after a SARS-CoV-2 infection but not after the vaccination [38]. Another limitation of the study is that almost all studies included did not test the included patients prospectively for the pre-morbid liability of thrombosis.

\section{Conclusions}

SARS-CoV-2 vaccinations can be complicated by VST. VST occurs at any age, predominantly after the first dose, predominatly in females, and with any of vaccine brands. Currently, more arguments in favour than against a causal relation between SARS-CoV-2 vaccination and VST can be raised. As post-vaccination VST may have a fatal outcome, treating physicians need to stay vigilant not to overlook VST and to start treatment in due time.

\section{Abbreviations}

CDC: Centers for Disease Control and Prevention; COVID-19: Coronavirus diseases 2019; CSF: Cerebro-spinal fluid; CT: Computed tomography; IVIGs: Intravenous immunoglobulins; PAI-1: Plasminogen activator inhibitor-1; PF: Platelet factor; SARS-CoV-2: Severe, acute, respiratory syndrome-coronavirus-2; VST: Venous sinus thrombosis.

\section{Acknowledgements \\ None}

\section{Authors' contributions}

JF: design, literature search, discussion, first draft, critical comments, SZ: literature search, discussion, critical comments, final approval. All authors ensure that this is the case. Both authors read and approved the final manuscript.

Funding

None received.

Availability of data and materials Not applicable.

\section{Declarations}

Ethics approval and consent to participate Not applicable. 


\section{Consent for publication \\ Not applicable.}

\section{Competing interests}

The authors declare that they have no competing interests.

\section{Author details}

${ }^{1}$ Klinik Landstrasse, Messerli Institute, Postfach 20, 1180 Vienna, Austria.

${ }^{2}$ University of Tunis El Manar and Genomics Platform, Pasteur Institute of Tunis, Tunis, Tunisia.

Received: 20 September 2021 Accepted: 3 December 2021

Published online: 20 December 2021

\section{References}

1. Roushdy T, Hamid E. A review on SARS-CoV-2 and stroke pathogenesis and outcome Egypt. J Neurol Psychiatr Neurosurg. 2021;57(1):63. https:// doi.org/10.1186/s41983-021-00319-y.

2. Medicherla CB, Pauley RA, de Havenon A, Yaghi S, Ishida K, Torres JL. Cerebral venous sinus thrombosis in the COVID-19 pandemic. J Neuroophthalmol. 2020;40:457-62.

3. Dakay K, Cooper J, Bloomfield J, Overby P, Mayer SA, Nuoman R, et al. Cerebral venous sinus thrombosis in COVID-19 infection: a case series and review of the literature. J Stroke Cerebrovasc Dis. 2021:30:105434.

4. Ciccone A. SARS-CoV-2 vaccine-induced cerebral venous thrombosis. Eur J Intern Med. 2021;89:19-21.

5. Zakaria Z, Sapiai NA, Ghani ARI. Cerebral venous sinus thrombosis 2 weeks after the first dose of mRNA SARS-CoV-2 vaccine. Acta Neurochir (Wien). 2021;163:2359-62.

6. Burley NB, Dy PS, Kalantri S, Razzaq K. Aortic Thrombosis and Acute Limb Ischemia Secondary to COVID Hypercoagulability. Cureus. 2021;13:e16171.

7. Steadman E, Fandaros M, Yin W. SARS-CoV-2 and plasma hypercoagulability. Cell Mol Bioeng. 2021;28:1-10. https://doi.org/10.1007/ s12195-021-00685-w.

8. Campello E, Simion C, Bulato C, Radu CM, Gavasso S, Sartorello F, et al. Absence of hypercoagulability after nCoV-19 vaccination: an observational pilot study. Thromb Res. 2021;205:24-8.

9. Bano F, Badugama B, Chandra D. Thrombosis and thrombocytopaenia after ChAdOx1 nCoV-19 vaccination: a single UK centre experience. BM Case Rep. 2021;14:e243894.

10. Ikenberg B, Demleitner AF, Thiele T, Wiestler B, Götze K, Mößmer G, et al. Cerebral venous sinus thrombosis after ChAdOx 1 nCov-19 vaccination with a misleading first cerebral MRI scan. Stroke Vasc Neurol. 2021. https://doi.org/10.1136/svn-2021-001095.

11. Tølbøll Sørensen AL, Rolland M, Hartmann J, Harboe ZB, Roed C, Jensen $T \varnothing$, et al. A case of thrombocytopenia and multiple thromboses after vaccination with ChAdOx1 nCoV-19 against SARS-CoV-2. Blood Adv. 2021:5:2569-74.

12. Suresh P, Petchey W. ChAdOx1 nCOV-19 vaccine-induced immune thrombotic thrombocytopenia and cerebral venous sinus thrombosis (CVST). BMJ Case Rep. 2021;14:e243931.

13. Ramdeny S, Lang A, Al-Izzi S, Hung A, Anwar I, Kumar P. Management of a patient with a rare congenital limb malformation syndrome after SARSCoV-2 vaccine-induced thrombosis and thrombocytopenia (VITT). Br J Haematol. 2021. https://doi.org/10.1111/bjh.17619.

14. Jamme M, Mosnino E, Hayon J, Franchineau G. Fatal cerebral venous sinus thrombosis after COVID-19 vaccination. Intensive Care Med. 2021:47:790-1.

15. Mehta PR, Apap Mangion S, Benger M, Stanton BR, Czuprynska J, Arya $R$, et al. Cerebral venous sinus thrombosis and thrombocytopenia after COVID-19 vaccination - A report of two UK cases. Brain Behav Immun 2021;95:514-7.

16. Wolf ME, Luz B, Niehaus $L$, Bhogal $P$, Bäzner $H$, Henkes $H$. Thrombocytopenia and intracranial venous sinus thrombosis after "covid-19 vaccine astrazeneca" exposure. J Clin Med. 2021:10:1599.

17. Castelli GP, Pognani C, Sozzi C, Franchini M, Vivona L. Cerebral venous sinus thrombosis associated with thrombocytopenia post-vaccination for COVID-19. Crit Care. 2021;25:137.
18. Esba LCA, AI JM. Reported adverse effects following COVID-19 vaccination at a tertiary care hospital, focus on cerebral venous sinus thrombosis (CVST). Expert Rev Vaccines. 2021;17:1-6. https://doi.org/10.1080/14760 584.2021.1940145.

19. Ciccone A, Zanotti B; working group on cerebral venous thrombosis after COVID-19 vaccination. The importance of recognizing cerebral venous thrombosis following anti-COVID-19 vaccination. Eur J Intern Med. 2021;89:115-117.

20. D'Agostino V, Caranci F, Negro A, Piscitelli V, Tuccillo B, Fasano F, et al. A Rare Case of Cerebral Venous Thrombosis and Disseminated Intravascular Coagulation Temporally Associated to the COVID-19 Vaccine Administration. J Pers Med. 2021;11:285.

21. Gattringer T, Gressenberger P, Gary T, Wölfler A, Kneihsl M, Raggam RB. Successful management of vaccine-induced immune thrombotic thrombocytopenia-related cerebral sinus venous thrombosis after ChAdOx1 nCov-19 vaccination. Stroke Vasc Neurol. 2021. https://doi.org/ 10.1136/svn-2021-001142.

22. Centonze L, Lauterio A, De Carlis R, Ferla F, De Carlis L. Successful liver transplantation from a donation after brain death donor with cerebral venous sinus and hepatic veins thrombosis occurred after ChAdOx1 nCov-19 Vaccination. Transplantation. 2021. https://doi.org/10.1097/TP. 0000000000003875.

23. Graf T, Thiele T, Klingebiel R, Greinacher A, Schäbitz WR, Greeve I. Immediate high-dose intravenous immunoglobulins followed by direct thrombin-inhibitor treatment is crucial for survival in Sars-Covid-19-adenoviral vector vaccine-induced immune thrombotic thrombocytopenia VITT with cerebral sinus venous and portal vein thrombosis. J Neurol. 2021;22:1-3. https://doi.org/10.1007/s00415-021-10599-2.

24. See I, Su JR, Lale A, Woo EJ, Guh AY, Shimabukuro TT, et al. US case reports of cerebral venous sinus thrombosis with thrombocytopenia after Ad26. COV2.S vaccination, March 2 to April 21, 2021. JAMA. 2021:325:2448-56.

25. Dutta A, Ghosh R, Bhattacharya D, Bhat S, Ray A, Pandit A, et al. Anti-PF4 antibody negative cerebral venous sinus thrombosis without thrombocytopenia following immunization with COVID-19 vaccine in an elderly non-comorbid Indian male, managed with conventional heparin-warfarin based anticoagulation. Diabetes Metab Syndr. 2021;15:102184.

26. Clark RT, Johnson L, Billotti J, Foulds G, Ketels T, Heard K, et al. Early outcomes of Bivalirudin therapy for thrombotic thrombocytopenia and cerebral venous sinus thrombosis after Ad26.COV2.S vaccination. Ann Emerg Med. 2021. https://doi.org/10.1016/j.annemergmed.2021.04.035

27. Aladdin Y, Algahtani H, Shirah B. Vaccine-induced immune thrombotic thrombocytopenia with disseminated intravascular coagulation and death following the ChAdOx1 nCoV-19 vaccine. J Stroke Cerebrovasc Dis. 2021;30:105938.

28. Walter U, Volmer E, Wittstock M, Storch A, Weber MA, Großmann A. Hirnvenen- und Sinusthrombose nach COVID-19-Schutzimpfung : Neurologisch-radiologisches Prozedere [Cerebral venous sinus thrombosis after COVID-19 vaccination : Neurological and radiological management]. Radiologe. 2021;29:1-10. https://doi.org/10.1007/s00117-021-00887-3.

29. Sheikh S. Thrombotic Thrombocytopenia and Central Venous Sinus Thrombosis Post - COVID-19 Vaccination and its Treatment with Heparin Alternatives. J Coll Physicians Surg Pak. 2021;31:149.

30. Schulz JB, Berlit P, Diener HC, Gerloff C, Greinacher A, Klein C, et al. Vaccination Study Group. COVID-19 vaccine-associated cerebral venous thrombosis in Germany. Ann Neurol. 2021. https://doi.org/10.1002/ana. 26172.

31. Krzywicka K, Heldner MR, van Kammen M, van Haaps T, Hiltunen S, Silvis SM, et al. Post-SARS-CoV-2-vaccination cerebral venous sinus thrombosis: an analysis of cases notified to the European Medicines Agency. Eur J Neurol. 2021. https://doi.org/10.1111/ene.15029.

32. Casucci G, Acanfora D. DIC-like syndrome following administration of ChAdOx1 nCov-19 vaccination. Viruses. 2021;13(6):1046. https://doi.org/ 10.3390/v13061046.

33. Ruf W. Links between complement activation and thrombosis. Blood 2019;134(suppl. 1): November $13^{\text {th }}$.

34. Maramattom BV, Moidu FM, Varikkottil S, Syed AA. Cerebral venous sinus thrombosis after ChAdOx1 vaccination: the first case of definite thrombosis with thrombocytopenia syndrome from India. BMJ Case Rep. 2021;14(10): e246455. https://doi.org/10.1136/bcr-2021-246455.

35. Introna A, Caputo F, Santoro C, Guerra T, Ucci M, Mezzapesa DM, et al. Guillain-Barré syndrome after AstraZeneca COVID-19-vaccination: a 
causal or casual association? Clin Neurol Neurosurg. 2021;208: 106887. https://doi.org/10.1016/j.clineuro.2021.106887.

36. Schultz NH, Sørvoll IH, Michelsen AE, Munthe LA, Lund-Johansen F, Ahlen MT, et al. Thrombosis and Thrombocytopenia after ChAdOx1 nCoV-19 Vaccination. N Engl J Med. 2021;3(384):2124-30.

37. Garaci F, Di Giuliano F, Picchi E, Da Ros V, Floris R. Venous cerebral thrombosis in COVID-19 patient. J Neurol Sci. 2020;15(414): 116871. https://doi. org/10.1016/j.jns.2020.116871.

38. Bikdeli B, Chatterjee S, Arora S, Monreal M, Jimenez D, Krumholz HM, et al. Cerebral venous sinus thrombosis in the U.S. population, after adenovirus-based SARS-CoV-2 vaccination, and after COVID-19. J Am Coll Cardiol. 2021;78:408-11.

\section{Publisher's Note}

Springer Nature remains neutral with regard to jurisdictional claims in published maps and institutional affiliations.

\section{Submit your manuscript to a SpringerOpen ${ }^{\circ}$ journal and benefit from:}

- Convenient online submission

- Rigorous peer review

- Open access: articles freely available online

- High visibility within the field

- Retaining the copyright to your article

Submit your next manuscript at $\boldsymbol{\nabla}$ springeropen.com 